\title{
SPIS RZECZY BĘDĄCYCH W POSIADANIU KOŚCIOLA PW. ŚW. PIOTRA I PAWLA W IMBRAMOWICACH SPORZĄDZONY DNIA 25 PAŹDZIERNIKA 1862 ROKU
}

W Archiwum Sióstr Norbertanek w Imbramowicach, w tece p.t. Spis rzeczy ofiarowanych do kościoła Norbertanek w Imbramowicach, przechowywany jest Rejestr wszystkich rzeczy kościelnych spisanych w roku 1862 dnia 25 październi$k a^{1}$. Inwentarz z 1862 r., sporządzony został w czasie, kiedy przełożoną klasztoru była Bronisława Switanowska ${ }^{2}$. W kronice klasztornej pod rokiem 1848 zapisano notatkę odnoszącą się do wyboru jej na stanowisko ksieni ${ }^{3}$. Najpierw wspomniano o śmierci poprzedniczki - Wiktorii Zdanowskiej: „31 października zmarła ksieni Wiktoria Zdanowska”, następnie podano informację, że: „12 grudnia obrana ksienią Bronisława Switanowska"”.

* Beata Skrzydlewska - dr historii sztuki, e-mail: bskrzydlewska@o2.pl

${ }^{1} \mathrm{~W}$ zbiorze tym znajdują się ponadto: Archiwum Norbertanek w Imbramowicach (dalej: ANI) Rejestr Generalny wszystkich rzeczy kościelnych spisanych roku Pańskiego 1781, a także Rejestr opisany wszystkich aparatów, srebra i relikwii, które znajduja się przy kościele naszym imbramowskim po śmierci świętej pamięci Matki naszej Dobrodziejki Jej Mości Panny Zofii Grothówny, ksieni imbramowski, dnia 26 czerwca Roku Pańskiego 1741, w: Spis rzeczy ofiarowanych do kościoła Norbertanek $w$ Imbramowicach; zob. także B. Skrzydlewska, Spis rzeczy podarowanych kościołowi $i$ klasztorowi norbertanek $w$ Imbramowicach $w$ latach 1712-1742, „Archiwa Biblioteki i Muzea Kościelne" (dalej: ABMK), 101 (2014), s. 217-232.

${ }^{2}$ Bronisława Switanowska profesję złożyła dnia 18 czerwca 1815 r., dnia 12 grudnia 1848 r. zostaje wybrana na ksieni klasztoru imbramowskiego, którą pozostaje aż do swojej śmierci, która nastąpiła dnia 11 sierpnia 1866 r., zob. ANI, Księga Profesji. Katalog Sióstr zmarłych od r.p. 1555, Klasztoru ss. Norbertanek w Imbramowicach pow. Olkuskiego, s. 67.

${ }^{3}$ Zob. ANI sygn. 35, Kronika retrospektywna za lata 1823-1917 spisana w 1924 r. przez Marie Lukaszewska, s. 145-187.

${ }^{4}$ Wiktoria Zdanowska habit zakonny przyjęła dnia 5 lutego 1786 r., profesję złożyła 28 kwietnia 1789 r. Na przełożoną zgromadzenia wybrana została 28 września 1831 roku. Zmarła po kilkumiesięcznej chorobie przed północą 31 października 1848 r. Zob. Księga Profesji. Katalog Sióstr, s. 59.

${ }^{5}$ Kronika retrospektywna za lata 1823-1917, s. 152. 
Okres rządów Bronisławy Switanowskiej był dla konwentu imbramowickiego czasem nieoczekiwanych zmian. Początkowo życie klasztorne toczyło się bez większych przeszkód. Dynamicznie funkcjonował prowadzony przez siostry 4klasowy Instytut Naukowy Wyższy Żeński, w którym wychowaniem zajmowały się norbertanki ${ }^{6}$. O popularności instytutu świadczył fakt, że w 1851 roku uczyło się w nim 37 kobiet, w roku 1852 były 52 uczennice, zaś w $1855-49^{7}$. Na utrzymanie klasztoru nadchodziły darowizny. 20 października 1849 r. Jadwiga z Siemieńskich Mieroszewska, zapisała testamentem 1200 złotych polskich - od których rocznie miało być wypłacane klasztorowi 600 złotych polskich na utrzymanie w instytucie ubogiej dziewczyny. ${ }^{8}$

Właśnie w czasach względnego dostatku dnia 25 października 1862 r., sporządzono spis rzeczy będących własnością klasztoru. Dowiadujemy się z niego, że kościół klasztorny był w posiadaniu następujących paramentów kościelnych: ornatów -43 , kap -10 , alb -23 , humerałów -29 , puryfikaterzy -45 , korporałów -17 , palek -50 , antepedii 41.

$\mathrm{Z}$ zakresu złotnictwa wpisano do inwentarza: lichtarze: srebrne -22 , cynowe -6 , drewniane 51 , porcelanowe 2 , z białej blachy 2 , blaszane -6 , mosiężny -1 ; kielichy -6 , monstrancje -1 , relikwiarze -4 , puszka 1 .

$\mathrm{W}$ rejestrze znajduje się jeszcze szereg innych przedmiotów, jak dywany, komże itp. Nie zostały natomiast uwzględnione obrazy i rzeźby. W kronice klasztornej z tego okresu nie umieszczono informacji na temat przekazywanych bądź kupowanych obiektów. Powodem tego jest fakt, że kronika opisująca ten okres ma charakter retrospektywny i spisana została dopiero w 1924 roku. Nie ma więc możliwości porównania rzeczy znajdujących się w spisie z kroniką jak np. miało to miejsce w przypadku Spisu rzeczy podarowanych kościołowi i klasztorowi norbertanek $w$ Imbramowicach $w$ latach 1712-1742. Tamten spis można było zestawić z kroniką spisaną za czasów ksieni Zofii Grothówny9.

Analizując inwentarz z 1862 r. zauważyć można, że niektóre rzeczy przekazywały lub wykonywały samodzielnie, zamieszkujące klasztor zakonnice: Tekla Bontani, Melania Kolarska, Zofia Malinowska, Elżbieta Lekszycka, Marianna Trzebińska ${ }^{10}$.

${ }^{6}$ W.W. Żurek, Historia klasztoru norbertanek w Imbramowicach, w: Zofia Grothówna, Kronika klasztorna sióstr norbertanek w Imbramowicach 1703-1741, wyd. W. Bielak, W. Żurek, Kielce 2011, s. XXXI; B. Skrzydlewska, Realizacja pedagogiki spotecznej Norbertanek imbramowickich na przykładzie Prywatnej Żeńskiej Szkoty Rolniczej w latach 1919-1949, w: Pedagogika spoteczna $w$ stużbie rodzinie. Aspekt pomocowy, kulturowy $i$ wychowawczy, pod red. K. Gąsior, T. Sakowicz, Kielce 2005, s. 245-254.

${ }^{7}$ Tamże, s. 153-154.

${ }^{8}$ Tamże, s. 152-153.

${ }^{9}$ ANI sygn. 27, Historya domowa klasztoru imbramowskiego Zakonu Premonstrateńskiego odemnie Zofii Grothówny xieni ręka własna pisana, i sobie dla pamięci y sukcessorkom dla informacyi dalszey zostawiona, a w roku Pańskim 1703 zaczęta, Imbramowice, 1703-1741; zob. także Zofia Grothówna, Kronika klasztorna sióstr norbertanek w Imbramowicach 1703-1741, wyd. W. Bielak, W. Żurek, Kielce 2011.

${ }^{10}$ Informacje dotyczące darczyńców zamieszczone zostały w przypisach odnoszących się bezpośrednio do Spisu rzeczy darowanych. 
Do rejestru z 1862 r. dopisano także obiekty, które klasztor pozyskał w latach: 1863, 1864, 1866 i 1867. Są to więc spisy pochodzące z okresu szczególnie trudnego dla klasztoru. Te wielkie zmiany dla konwentu zapoczątkował wybuch powstania styczniowego. Dnia 16 sierpnia 1863 r. w Imbramowicach miała miejsce krwawa bitwa między Polakami a wojskami rosyjskimi. Według informacji zawartej w kronice, bitwa była na tyle poważna, że ocalenie klasztoru uznano za cud $^{11}$. Jednak wyjątkowo krytycznym dla Imbramowic był rok 1864. Po klęsce powstania styczniowego wydano nakaz zamknięcia klasztoru ${ }^{12}$.

Jak wynika z rejestrów, w tamtym okresie darowizny również pochodziły od norbertanek imbramowickich: Emilii Stankur, Emilii Dudzicz i ksieni Bolesławy Switanowskiej. Na własność klasztoru przeszły także obiekty przekazane przez siostry norbertanki z Pińczowa (Buska) Teklę Jarecką, Mariannę Garlicką i Anielę Olsztyńską, które w ramach likwidacji klasztorów przywieziono do Imbramowic w 1864 r. ${ }^{13}$ Ostatnie dwa spisy pochodzą z lat: 1866 i 1867. Pierwszy sporządzony został tuż po śmierci ksieni Bronisławy Switanowskiej. O śmierci ksieni w kronice odnotowano, że: „11 lipca Jej Mość ksieni Bolesława Switanowska po 13-to miesięcznej chorobie przeszła do Pana po nagrodę cnót i zasług swoich o godz. 11 przed południem"'14. Poniżej zapisano, że: „28 sierpnia obrana przełożoną p. Marianna Trzebińska". W tym czasie po zmarłych norbertankach przekazywano różne przedmioty na rzecz kościoła; przekazała je między innymi ksieni Marianna Trzebińska.

Przygotowując poniższy tekst do druku, zastosowano się do wymogów Instrukcji wydawniczej dla źródet historycznych od XVI do połowy XIX wieku ${ }^{15}$. Pisownię nazwisk ujednolicono. Z lewej strony tekstu (czasem w tekście) wpisano wytłuszczoną czcionką paginację, która została dodana przez zakonnice później. Wytłuszczono także lata wpisu i nagłówki. Wiadomości odnoszące się do sióstr imbramowickich podawane są w przypisach, na podstawie „Księga Profesji. Katalog sióstr zmarłych od r. p. 1555 Klasztoru ss. Norbertanek w Imbramowicach pow. Olkuskiego"16.

W tekście znajduje się duża ilość terminów z zakresu włókiennictwa. Podany termin objaśniony został $\mathrm{w}$ przypisie tylko jeden raz, jeśli pojawia się on w tekście w innych miejscach nie wprowadzano już odnośników. Definicję nieużywanych współcześnie pojęć przytaczano głównie na podstawie wydanego przez Bibliotekę Muzealnictwa i Ochrony zabytków, Stownika terminologicznego wtókiennictwa, autorstwa Marty Michałowskiej a także Stownika terminologicznego sztuk pięknych pod redakcją Stefana Kozakiewicza ${ }^{17}$.

${ }^{11}$ Kronika retrospektywna za lata 1823-1917, s. 155.

${ }^{12}$ Ostatnimi nowicjuszkami, które przyjęły habit zakonny przed zamknięciem nowicjatu były Melania Kolarska i Maria Niecka (ksieni w latach 1890-1917), zob. j.w. s. 154.

${ }^{13}$ Kronika retrospektywna za lata 1823-1917, s. 155-156.

${ }^{14}$ Tamże, s. 155.

${ }^{15}$ Kazimierz Lepszy, Instrukcja wydawnicza dla źródet historycznych od XVI do połowy XIX wieku, Wrocław 1953.

${ }^{16}$ Księga Profesji. Katalog sióstr.

${ }^{17}$ M. Michałowska, Stownik terminologiczny włókiennictwa, Warszawa 1995; Stownik terminologiczny sztuk pięknych, pod red. S. Kozakiewicza, Warszawa 1976. 


\section{Rejestr wszystkich rzeczy kościelnych spisanych w roku 1862 dnia} 25 października

Ornatów białych

na uroczystości Świąt wielkich

Ornat $\mathrm{z}$ dalmatykami na białej materii haftowany 1

Ornat $\mathrm{z}$ dalmatykami materia $\mathrm{w}$ kwiaty srebrne $\mathrm{i}$ jedwabne 1

Ornat bez dalmatyk, słup biały, haftowany, boki materii bladoniebieskiej 1

Na mniejsze święta

koloru białego

Ornatów $6^{\mathrm{a}}$

Na niedziele

Ornatów 3

Na dole w zakrystii do

codziennego użytku

Ornatów 2

Ornat jeden ma kolor biały, haftowany jedwabiem, ale bardzo zły, którego się wcale nie używa ${ }^{\mathrm{b}}$.

\section{Ornatów czerwonych}

Ornat aksamitny z dalmatykami 1

\section{[s. 28]}

Ornat $\mathrm{z}$ dalmatykami, materia srebrem przerabiana 1

Ornatów bez dalmatyk na święta mniejsze 4

Ornatów 2, też na kolor czerwony, ale nie mających potrzeb ${ }^{18}$ drobiazgowych, są wcale nie używane.

\section{Na dole w zakrystii}

Ornat 1 czerwony

Ornat czerwony nie używany stary 1 , spruty i ufarbowany

Ornatów fioletowych 5

Ornatów zielonych 3

Ornatów czarnych 4

$\mathrm{Na}$ dole w zakrystii ornat fioletowyc.

\section{Ornatów czarnych}

Ornat z dalmatykami, słupy krzyżową robotą haftowane boki manszestrowe $1^{19}$

Ornat ze słupem aksamitnem ciemno fiałkowem ${ }^{20} 1$

Ornat z materii w białe wyrabiane kwiaty 1

Ornat $\mathrm{z}$ dalmatykami aksamitny już nie używany 1

a Skreślona cyfra 5.

${ }^{\mathrm{b}}$ Całe zdanie dopisane poprzecznie z prawej strony.

${ }^{\mathrm{c}}$ Całe zdanie dopisnae poprzecznie z prawej strony.

${ }^{18}$ Potrzeby-wszycia taśmowe ze sznureczków pasamonicznych z odpowiednimi guzami, dodat-

kami, wytwarzane zwykle przez pasamoników.

${ }^{19}$ Manczester - angielska tkanina bawełniana.

${ }^{20}$ Kolor fiałkowy (od fiołek) - fioletowy z zimnym odcieniem. 


\section{Na dole w zakrystii}

Ornat z materii w białe przerabiane kwiaty 1

Kap na kolor biały 3

Kap nie do używania 2

[s. 29]

Kap czerwonych 2

Fioletowa 1

Czarne 2, ale bardzo liche

Dywanów 7

Sukno stare przed wielki ołtarz

Dywaników do codziennego użytku 3

Dywanik na Wielki Piątek pod krzyż Pana Jezusa na kościół 1

Zasłony na troje drzwi

Płaszczyków zielonych 3

Zasłona do wielkiego ołtarza szafirowa dziurawa 1

Na ubranie ołtarzyka na Święta Wielkanocne na środek kościoła kawałków 2, niegdyś z antepedii ale bardzo brudne i dziurawe;

\section{Całun 1}

Opon $^{21}$ z obicia kościelnego podszytego płótnem do użycia na Boże Ciało 4. Bielizna kościelna

Alb nowych płóciennych z koronami szerokiemi 2

Alba muślinowa z koroną też szeroką 1

Alb płóciennych dobrych 2; webowa ${ }^{22} 1$

Alb perkalowych dobrych 3

Alb płóciennych cerowanych i łatanych 11

Alba złotem haftowana 1 i muślinowych starych 3

Komży 5

Rokiet 5

Humerałów nowych 16

Humerałów starych 13

Obrusów nowych 2

Obrusów starych 18

Obrusów do kapitularza 5

Obrusów do kaplicy 2, potargane

Ręczników 24

Ręczników 25

Ręczników haftowanych płóciennych 24

Puryfikaterzy 45

Korporałów 17

Palek 50

${ }^{21}$ Opona - nazwa używana w Polsce w XVI-XVIII w. na określenie tkanin służących do ozdabiania ścian lub jako kotary, cyt. za Stownik terminologiczny sztuk pięknych, red. S. Kozłowski, Warszawa 1976, s. 336.

${ }^{22}$ Weba - bardzo cienkie lniane płótno, używane na bieliznę pościelową, zob. Słownik języka polskiego, t. 3, red. M. Szymczaka, Warszawa 1996, s. 626. 
Pasków wełnianych 4

[s. 30]

Pasków niciowych 2

Pasków bawełnianych 3

Kap chłopskich z kapturami 4

Kap z pelerynką 9

Komży dla chłopców 8

Pokrowce na lichtarze dwa srebrne 16

Pokrowce na poduszki 4

Pokrowce na stołki, czyli krzesła dla księży w czasie kazania siedzących 6

Poduszek aksamitnych czerwonych 5

Poduszek haftowanych 6

Poduszka czarna 1

Poduszek codziennych 7

Krzeseł aksamitnych czerwonych 3

Krzeseł haftowanych na biały kolor 3

Krzesło z poręczami z ptaszkiem haftowanym 1

Lichtarzy dużych srebrnych 6

Lichtarzy mniejszych, małych do świec woskowych 12

Lichtarzy z wielkiego ołtarza cynowych 6

Lichtarzy drewnianych z ołtarzy 30

Lichtarzy drewnianych od katafalku 21

Miednica do zakrystii cynowa z brzegiem zepsutym 1

Kufel do wody cynowy 1

Miednic przy ołtarzach miedzianych 6

Kociołek na wodę święconą miedziany 1

Dzbanki miedziane 2

Lustro w zakrystii wytarte 1

Kanon na wielki ołtarz pokapany

Szczypców par 2 kościelnych

Pudełko drewniane stare na hostie do Mszy świętej

Tacka cynowa 1

[s. 31]

Talerzyk cynowy 1

Tacki pod ampułki cynowe 2

Tacka srebrna z ampułkami złoconemi 1

Tacka srebrna z ampułkami srebrnemi 1

Ampułek szklanych par 2

Tacka cynowa większa niż do ampułek 1

Kufel cynowy 1

Wazoników cynowych do kwiatków 4

Dzwonków do ołtarzy: dwa duże i dwa małe

Kubek porcelanowy 1

Lichtarze porcelanowe 2

Profitek blaszanych 21 
Profitek szklanych popękanych 4

Podstawek z lichtarzami pod monstrancję srebrną

Podstawek pod lampkę do chóru srebrna

Lampka przed kapitularz 1

Przed Matkę Boską przed furtę srebrna

Trybularz i łódka do kadzidła posrebrzane

Zacheuszki drewniane 12

Lichtarze z białej blachy 2

Do świec wosk

Kielichów 5

Patena do komunii świętej 1

Monstrancja 1

Relikwiarz Drzewa Krzyża Świętego

Kolumna oprawna

Relikwiarz Świętego Kajetana oprawny w srebrną monstrancję

Relikwie oprawne za szkłem w formie pudełek

Mszał oprawny w czerwony safian z klamrami srebrnymi 1

Mszałów wszystkich 4

Puszka cynowa na olej święty 1

Lichtarzy blaszanych do chóru 5 i na środek chóru 1

Blacha miedziana do chędożenia korporałów 1

Kociołek cynowy do święconej wody mały 1

[s. 32]

Tuwalni ${ }^{23}$ muślinowych 5

Subkorporałów lino batystowych haftowanych 6

Starych 13

Listewek do obszycia stuł 60

Koron siatkowych powszywanych do alb 10

Szydełkowa 1 robiona przez siostrę Teklę Bontani ${ }^{24}$

Korony wszystkie w komży szydełkowe też przez nią robione

Korona szydełkowa w gwiazdki robiona szeroka do alby, przez siostrę Melanię

Kolnarską ${ }^{25} 1$ Warsztankowych koron 2

Tasiemkowa czy klockowa staroświecka 1

Na płótnie wyciągane nitki robione 1.

Przykrycia pod patenę do Komunii Świętej 3

Do przykrycia jak drzewo Krzyża Świętego ksiądz nam podaje całować 1

Korporałów pod patenę 2

Antepedii czarnych 6

$\mathrm{Na}$ Boże Ciało antepedii 4

${ }^{23}$ Tuwalnia - welon naramienny. Pas tkaniny trzymany przed przyjmującym Komunię św.

${ }^{24}$ Tekla Bontani profesję przyjęła dnia 25 września 1863 r., zmarła dnia 20 grudnia 1863 r., w wieku 42 lat, zob. Księga Profesji. Katalog sióstr, s. 70.

${ }^{25}$ Melania Kolnarska obłóczyny: 17 kwietnia 1860 r., zmarła po trzech latach pobytu w zakonie dnia 18 grudnia 1862 r., w wieku 42 lat (w zakonie przebywała 3 lata), zob. Księga Profesji. Katalog sióstr, s. 75. 
Antepedii z białej materii na uroczystości 6

Antepedii aksamitnych czerwonych na uroczystości 6

Antepedia na mniejsze święta przed wielki ołtarz jedwabna brudna 1

Antepedia Przed Matkę Boską haftowana na białej materii 1

Antepedii codziennych 13, z których tylko 6 się używa a reszty niepodobna zakładać, bo bardzo brudne

Do kapitularza antepedii 4

[s. 33]

Baldach 1

Umbraculum 2 - jedna srebrna i jedwabiami haftowana staroświecka, druga haftowana przez siostrę Elżbietę Lekszycką ${ }^{26}$

Baldach taż sama siostra robiła

Tuwalnia jedwabna, niebieska do okrycia księdza na Boże Ciało do wzięcia monstrancji 1, też roboty siostry Elżbiety Lekszyckiej ${ }^{27}$

Dwa wota srebrne serduszka, jedno przypięte do boku Pana Jezusa w kapitularzu, drugie u boku Pana Jezusa Miłosiernego na korytarzu przed chórem wiszącego

Lichtarz mosiężny do zakrystii na dole 1

Dzwonek mały w zakrystii na górze 1

Firanki zielone 4

Firanki muślinowe na dwa feretrony

Firanki jedwabne wypełznięte do Grobu Chrystusowego na wielki piątek

Kielich cynowy z przykrywką na wielki ołtarz 1

Paski do dzwonka 2

Korzec żelazny

Rurki do robienia świec blaszane 1

[s. 36] $]^{\mathrm{d}}$

Z sześciu pokrowców ze stołków płótna spod całunu płachty jednej zrobiłam ścierek 2 Siennik dla służącej należącej do posługi kościelnej

Sukno zielone na gradusy przed wielki ołtarz podszyłam i resztę do antepedii papierowych użyłam.

Z pięciu obrusów grubych i rzadkich zrobiłam sześć przykryć na ołtarze

Oddałam wazoniki cynowe 4, a na miejscu tychże wzięłam kufel cynowy z przykryciem, więc w zakrystii są dwa kufle cynowe z przykryciami

Materii mieniącej łokci 18

Materii z sukni brytów 3 i falbany łokci 8 ".czerwonego łokci 12

Aksamitu wełnianego na wyklejenie podstawek pod monstrancje

$\mathrm{Na}$ welonach manszestru do ornata czerwonego

Aksamit czarny z ornata

Materia $\mathrm{z}$ ornata czerwonego farbowana

Szalik czarny farbowany na słup do ornata

${ }^{\mathrm{d}}$ Brakuje stron 34 i 35.

${ }^{26}$ Elżbieta Lekszycka, habit zakonny przyjęła 25 października 1836 r., profesję uczyniła $14 \mathrm{X}$ 1839 r., zmarła 13 stycznia 1895 r. w wieku 75 lat, zob. Księga Profesji. Katalog sióstr, s. 69.

${ }^{27}$ Tamże. 
Tybeta ${ }^{28}$ biaůego brytów 4 " stanik i rćkawy

Muślin dwa bryty z sukni

Adamaszek fiałkowy z ornata

[s. 37]

Siostra Tekla Bontani ${ }^{29}$ dała do zakrystii od 28 października r. 1852:

Dwie komże, czyli rokiety muślinowe z koronami i wstążkami

Tuwalnię jedną muślinową haftowaną

Sześć tuwalni webowych ${ }^{30}$ haftowanych

Puryfikaterzy webowych haftowanych

Cztery komeżki płócienne haftowane, z których dwie ona sama wyhaftowała

Flaszek dwanaście na cienie ${ }^{31}$.

Odsrebrzyć dała lampę z chóru, lampkę sprzed kapitularza, lampę Matki Boskiej sprzed furty i podstawek z lichtarzami do monstrancji.

Lichtarzy nowych srebrnych cztery do świec woskowych

Profitek szklanych 10

Antepedia ceratowa do kapitularza

Obrusków perkalowych cztery haftowanych do kapy, z których dwa sama wyhaftowała. Dywan pąsowy przed ołtarz Świętego Kajetana

Ceratę czarną na obicie w kościele wystawki zniszczonej.

Słomiankę do wycierania nóg, nici tasiemek bawełny jedwabiu żółtego i czarnego za rubli srebrny trzy.

Nożyczki małe

Ornat czerwony słup krzyżową robotą haftowany boki z materii

Ornat czarny, słup aksamitny ciemno fiałkowy, boki manszestrowe

Szkła do trzech ramek do zakrystii na dole florenów 6

Ornat biały na białej materii haftowane kłosy i winogrona kielich na środku [s. 38]

Siostra Melania Kolnarska ${ }^{32}$ dała do zakrystii:

Albę webową z koroną szydełkową jej roboty

Dywan - na czarnem tle bukiety z kwiatów - strzyżony

Przed Świętego Józefa, lichtarzy nowych srebrnych do małych świec woskowych

6 i profitki szklane do tychże lichtarzy 6

Glafonu czarnego do sporządzenia antepedii - czarnych łokci 5

Sznureczka białego do obszywania komży sztuczkę całą.

${ }^{28}$ Tybet - 1. Cienka, miękka tkanina z wełny czesankowej owiec lub kóz tybetańskich, o splocie skośnym dwustronnym. Pod koniec XIX w. bywała tez wzorzysta, przeważnie w kwiaty. 2. Cięższa tkanina wełniana o splocie skośnym, używana na odzież wierzchnią.

${ }^{29}$ Zob. przypis 23.

${ }^{30}$ Weba - najcieńsza, gęsta tkanina lniana o splocie płóciennym, bielona. Używana od XVI w. zwykle na bieliznę osobistą, obecnie pościelową.

${ }^{31} \mathrm{~W}$ dalszej części wykreślone zostały dwie linijki tekstu: „Kosz na bieliznę kościelną do święcenia, wanienkę blaszaną lakierowaną do święcenia wody"

${ }^{32}$ Zob. przypis 25 . 
Siostra Zofia Malinowska ${ }^{33}$ dała sztukę płótna na obrusy, z których zrobiłam $5^{\mathrm{e}}$

Siostra Elżbieta Lekszycka ${ }^{34}$ dała wstążkę szafirową do komży

Siostra Marianna Trzebińska ${ }^{35}$ dywan przed Świętą Annę

Pensjonarek kilka złożyło się na dywan przed Matkę Boską.

[1863]

Rok Pański 1863

Zakonnice z Pińczowa dały:

Dwa lichtarze srebrne i pastorał $\mathrm{z}$ białej blachy posrebrzanej ${ }^{\mathrm{f}}$

Tackę miedzianą 1

Tackę z prostej blachy 1

Zacheuszki mosiężne 10 całych [s. 39], jedenasty złamany, dwunastego całkiem brak

Pani Barska dała sześć rulonów papierowego obicia na dwa parawany na ubranie ołtarzy na Boże Ciało.

[1864]

Rok 1864

Zakonnice z Pińczowa dały ${ }^{36}$ :

Jedno antepedium do wielkiego ołtarza, na białej materii haftowane szydełkiem jedwabiami, już nie nową, ale brudną.

Dywanik na szafirowem suknie szydełkiem wyszywany już też bardzo od moli przedziurawiony, z którego zrobiła się antepedium przed wielki ołtarz.

Siostra Emilia Stankur ${ }^{37}$ dała wstążkę do komży niebieską z czarnemi brzegami. Zakonnice pińczowskie dały: korale do Matki Boskiej, którą z sobą przywiozły - sznurków sześć dobrych, które są zawieszone na szyi Matki Boskiej i Pana Jezusa. Cztery sznurki bardzo robaczywe i nierówne bardzo, wielkości tej samej jak na Matce Boskiej i trzy sznureczki drobnych.

[s. 40]

W roku 1864 dostałam od N.P. Ksieni Bolesławy Switanowskiej ${ }^{38}$ :

Dywan czerwony w ciemne desenie, strzyżony

Sztukę płótna, z której pięć obrusów (zrobiłam)

Krzyż duży, którego używają w czasie procesji pogrzeba.

Pas białej morwy, sznur jedwabny karmazynowy i cztery kutasy ${ }^{\mathrm{g}}$ smelkowe od

${ }^{\mathrm{e}} \mathrm{W}$ dalszej części wykreślone zostały cztery wyrazy „na komże lino batysta”.

${ }^{\mathrm{f}}$ Kolejne zdanie wykreślone: „blacha miedziana do czyszczenia korporałów”

${ }^{\mathrm{g}}$ Wykreślony wyraz

${ }^{33}$ Zofia Malinowska obłóczyny 11 lipca 1848; profesja 7 sierpnia 1849 r., zmarła 27 stycznia 1894 r. Zob. Księga Profesji. Katalog sióstr s. 73.

${ }^{34}$ Zob. przypis 26.

${ }^{35}$ Marianna Trzebińska obłóczyny 21 maja 1844 r., profesja 20 VIII 1845, 18 sierpnia 1866 wybrana została przełożoną zakonu, zmarła 26 października 1882 r. Zob. Księga Profesji. Katalog sióstr, s.72.

${ }^{36}$ Zob. przypis 12.

${ }^{37}$ Emilia Stankur - śluby wieczyste złożyła 19 marca 1844 r., zmarła 1 stycznia 1906 r. w wieku 86 lat. Zob. Księga Profesji. Katalog sióstr, s. 71.

${ }^{38}$ Zob. przypis 2. 
siostry Dudzicz ${ }^{39}$. Galonków żółtych szychowych wąskich 3 całe sztuczki szerokiego, jedna cała sztuczka i drugiej mało co napoczętej.

Kancjonał skradziony; korona od alby złotem haftowanej jest w komży płóciennej, od muślinowej, która się nie używała jest wzięta do alby płóciennej.

Miednicę jedną mosiężną dała mi Panna Ksieni.

[s. 41]

[1863]

W roku $1863^{\text {h }}$

Najprzewielebniejsza Panna Ksieni Bronisława Switanowska ${ }^{40}$ dała na zakrystię po zmarłej siostrze Kolnarskiej ${ }^{41}$ prześcieradeł 3 , a (z) tych jest alb 2.

Po siostrze Bontani ${ }^{42}$ prześcieradeł 5 , z tych są alb 2 i na komeżkę jedna, fartuchów 3, z których jest komża.

Po Siostrze Marciszewskiej ${ }^{43}$ :

Fartuchów 2

Podbrodników 6

Spódnic 4, z trzech brytów każda spódnica

Zatyczek długich 4, małych 2, jedna jest cała a z drugiej zrobiłam rękawy do alby.

\section{[1866]}

W roku $1866^{\mathrm{i}}$

Najprzewielebniejsza Panna ksieni Maria Trzebińska ${ }^{44}$ dała do zakrystii, po zmarłej ksieni Bronisławie Switanowskiej5 ${ }^{45}$ pięć fartuchów i dwa prześcieradła.

Po Siostrze Kolnarskiej ${ }^{46} 4$ zatyczki, z których alba skrojona, z fartucha na duże komże będą.

Ze szkolnych rzeczy dostałam na użytek zakrystii:

Mosiężna tacka z 6 lichtarzami

Wanienka miedziana

Kosz duży z przykryciem

Firanka do okna drelichowa w paski

Miednica mosiężna duża do prania puryfikaterzy i miednica z cynkowej blachy jedna, [] dwie małe, jedna mała mosiężna.

\footnotetext{
${ }^{\mathrm{h}}$ Rok wpisany poprzecznie z lewej strony. Rok 1863 występował już wcześniej w tekście.

${ }^{i}$ Rok wpisany poprzecznie, $z$ lewej strony.

${ }^{39}$ Emilia Dudzicz - habit przyjęła dnia 8 grudnia 1837 r., profesje uczyniła 21 stycznia 1839 r., zmarła dnia 7 czerwca 1881 r.. Zob. Księga Profesji. Katalog sióstr, s. 70.

${ }^{40}$ Zob. przypis 2.

${ }^{41}$ Zob. przypis 25.

${ }^{42}$ Zob. przypis 24.

${ }^{43}$ Józefa Marciszewska, przyjęła profesję dnia 8 grudnia 1837 r., zmarła 31 października 1865 r. Zob. Księga Profesji. Katalog sióstr, s.70.

${ }^{44}$ Zob. przypis 35.

${ }^{45}$ Zob. przypis 2.

${ }^{46}$ Zob. przypis 25 .
} 
$[$ s. 43]

[1867]

Bielizna kościelna opisana w r. 1867

Obrusów: nowych 10, starych 13, na ołtarz w oratorii 2, w kapitularzu 5, w kaplicy haftowanych 4 , alb 25 płóciennych, obrusów na wielki ołtarz 4.

Ręczników a obrusów szkolnych 13, ręczników starych 12, ręczników haftowanych 24, gładkich 42.

Puryfikaterzy haftowanych 13, obszywanych tiulikami 46

Humerałów nowych 18, starych 8

Komży 14

Korporałów haftowanych złotem 2, obszywanych siateczkami 13

Palek 70

Listewek na stuły 70

Subkorporałów lino batystowych haftowanych 6

Tuwalnia płócienna, haftowana na ołtarz Matki Boskiej w oratorii od Siostry Oraczewskiej ${ }^{47}$.

Alb 5 - wydane o. Reformatom

Na przykrycie antepedii płóciennych płacht 8 , z obrusów 4

Firanki do kapitularza zielone dwie i do zakrystii na dole dwie

Dwa kawałki czarnego merynossa ${ }^{48} \mathrm{i}$ dwa kawałki glassa czerwonego starego.

Słowa kluczowe: Bronisława Switanowska, Imbramowice, powstanie styczniowe, rejestr, rzeczy darowane, norbertanki z Buska, ornat, alba, lichtarz, kielich, puryfikaterz

j Strona 42 nie zapisana.

${ }^{47}$ Anna Oraczewska, habit zakonny przyjęła 24 września 1854 r., profesję uczyniła 1856 r. Dnia 1 lutego 1882 roku, wybrana została ksieni klasztoru. Funkcję tę pełniła do swej śmierci - 16 października 1890 r. Zob. Księga Profesji. Katalog sióstr, s. 74.

${ }^{48}$ Delikatna wełna z owcy pochodzącej z Hiszpanii. Owca merynosowa, wełna merynosowa, zob. Stownik języka polskiego, t. 2, s. 133. 


\section{THE LIST OF THINGS THAT ARE IN POSSESSION OF THE CHURCH OF STS PETER AND PAUL IN IMBRAMOWICE MADE ON 25 OCTOBER, 1862}

\section{Summary}

In the Archive of the Norbertine Sisters in Imbramowice in the folder entitled The list of things donated to the church of the Norbertine Sisters in Imbramowice there is The register of all church things written on 25 October, 1862.

The inventory of 1862 was drawn up when Bronisława Switanowska was the superior of the convent. The period of her reign was the time of changes for the convent in Imbramowice. At first there were no major obstacles in monastic life, and in those times of relative prosperity on 25 October, 1862 a list of things belonging to the convent was made. We learn from it that the convent church was in possession of the following church vestments: chasubles -43 , copes -10 , albs -23 , amises -29 , purificators -45 , corporals -17 , palls -50 , antependia 41.

Under the goldsmithery the entry includes: candlesticks: silver -22 , tin -6 , wooden 51 , porcelain -2 , tinplated -2 , metal -6 , brass -1 ; b) chalices -6 , c) monstrances -1 , reliquaries -4 , a pyx -1

The register also contains a number of other items, such as carpets, surplices, etc. Paintings and sculptures are not included. This register is particularly valuable because the chronicles relating to that period were written only in 1924, therefore, they are of a retrospective type. Analyzing the inventory of 1862, it can be noticed that some things were given or done by the nuns living in a convent. The register also includes the objects that convent acquired in 1863, 1864, 1866 and 1867. Those are the inventories from the period particularly difficult for the convent. The January Uprising initiated great changes. And the year 1864 was extremely critical for Imbramowice as it was then when, after the collapse of the uprising, the convent was ordered to be close down. As the records show at that time donations also came from the Norbertine Sisters in Imbramowice. In addition, the Norbertine Sisters of Pinczów (Busk) after the liquidation of their convent brought their possession to Imbramowice in 1864. The last two registers come from the years 1866 and 1867.

Keywords: Bronisława Switanowska, Imbramowice, the January Uprising, register, donated things, the Norbertine Sisters from Busko, chasuble, alb, candlestick, chalice, purificator 